Artículo

\title{
Impacto económico, demográfico y social de la pandemia de gripe española en Bizkaia (1918-1920)*
}

\author{
Mikel Erkoreka** ID \\ UPV/EHU. Centro de Documentación e Investigación del Concierto Económico y las Haciendas Forales
}

\section{Josu Hernando (DD}

UPV/EHU. Basque Museum of the History of Medicine

Eduardo J. Alonso (DD

UPV/EHU. Centro de Documentación e Investigación del Concierto Económico y las Haciendas Forales

\section{Anton Erkoreka $\mathbb{D}$ \\ UPV/EHU. Basque Museum of the History of Medicine}

\section{INFORMACIÓN DEL ARTÍCULO}

\section{Historia del artículo:}

Recibido: 7 de junio de 2020

Aceptado: 2 de noviembre de 2020

On-line: 12 de abril de 2021

\section{Códigos JEL}

H51, I18, J1, N34

\section{Palabras clave}

Gripe española, Pandemias, Economía,

Hacienda pública

\begin{abstract}
R E S U M E N
El artículo analiza las consecuencias sanitarias y demográficas de la pandemia de gripe española en Bizkaia en relación con indicadores económicos, laborales y hacendísticos. Primeramente, se analiza la evolución y distribución de las tasas de mortalidad atribuibles a la pandemia. El impacto en la mortalidad fue mayor en los municipios industriales, apreciándose una relación entre el tamaño y la densidad de población y la incidencia de la pandemia. En segundo lugar, se analiza el impacto de la pandemia sobre la economía provincial. El artículo concluye que el sector empresarial y la hacienda pública vizcaína no sufrieron de manera ostensible el impacto de la pandemia sobre sus cuentas y actividad. El análisis demográfico y sanitario se basa principalmente en el Registro Civil y el Boletín Estadístico de Bilbao. El análisis económico y presupuestario se fundamenta en la documentación empresarial y las fuentes oficiales y presupuestarias de las principales instituciones públicas vizcaínas.
\end{abstract}

(c) 2020 Asociación Española de Historia Económica

\section{The economic, demographic and social impact of the Spanish influenza in Bizkaia (1918-1920)}

\section{A B S T R A C T}

The article analyses the health and demographic consequences of the pandemic in Bizkaia (1918-1920) in relation to economic, labour and treasury indicators. Firstly, the article studies the evolution and distribution of the mortality rates that can be attributed to the flu pandemic. The impact on mortality was greater in the more industrial municipalities and a relation can be appreciated between population size and density and the incidence of the pandemic. Secondly, the article analyses the pandemic's impact on the provincial economy. The article concludes that the business sector and the public finances of the main institutions of Biscay did not suffer significantly from the pandemic's effects. The demographic and health analysis employs two main sources: the Civil Registry and the Statistical Bulletin of Bilbao. The budgetary and accountancy analysis are based on business statistics and documentation and official and budgetary sources of the main public institutions of Bizkaia.

(c) 2020 Asociación Española de Historia Económica

\footnotetext{
* El trabajo forma parte de la actividad investigadora de los Grupos de investigación Biography and Parliament (ref. IT 1263-19) y Demografía Histórica e Historia Urbana (ref. GIU 18-144) de la UPV/EHU, y del proyecto «Biografía colectiva y análisis prosopográfico más allá del Parlamento» (ref. PGC2018095712-B-100) del Ministerio de Ciencia, Innovación y Universidades.

** Autor para correspondencia.

Correo electrónico: mikel.erkoreka@ehu.eus (Mikel Erkoreka)
} 


\section{Introducción}

Las epidemias y pandemias han sido recurrentes en la historia de la humanidad. La evolución de nuestras sociedades en el último milenio ha estado marcada por la peste, viruela, cólera, tuberculosis, gripe... hasta llegar a la pandemia de la COVID-19. Las crisis sanitarias han condicionado la evolución tanto de la esfera pública como privada de nuestras sociedades afectando a múltiples ámbitos como la asistencia sanitaria, la política, la economía, el urbanismo o la hacienda pública.

La pandemia de la COVID-19, al igual que otras pandemias en el pasado, ha provocado un estado general de alarma e incertidumbre. Centrándonos en su vertiente económica y social, las interrogantes sobre su alcance han inundado todos los ámbitos de la esfera pública y privada: ¿cómo afectará a la actividad empresarial y el empleo?, ¿qué impacto tendrá sobre la desigualdad?, ¿qué políticas públicas deben aplicarse para afrontar la crisis social y sanitaria?, ¿cómo se financiarán estas políticas?

Aunque el futuro es impredecible, estudiar las pandemias del pasado resulta una herramienta práctica y útil para extraer lecciones ante los retos presentes y futuros. A raíz de la pandemia de la COVID-19, el interés por el análisis de las pandemias del pasado ha resurgido con fuerza. Por su proximidad temporal y los paralelismos que guarda con la pandemia de la COVID-19, la pandemia de gripe española de 1918-1920 ha recibido una especial atención.

Las investigaciones sobre la gripe española recibieron un impulso reciente en el contexto del centenario de la pandemia (Echeverri, 2018). Tras la aparición de la COVID-19, han proliferado nuevas investigaciones que basándose en el análisis del impacto económico, social y demográfico de la gripe española, abren la vía para plantear hipótesis y escenarios futuros sobre los efectos de la COVID-19 (Barro, Ursúa y Weng, 2020; Goldstein y Lee, 2020; Athukorala y Athukorala, 2020). En el ámbito español, también se ha investigado sobre los efectos de la gripe española en busca de paralelismos con la pandemia de la COVID-19 (Basco, Domenech y Roses, 2020; Erkoreka, 2020).

En línea con esta renovada corriente de investigación sobre la gripe española, el objetivo de este artículo es analizar el impacto de dicha pandemia en Bizkaia aplicando un enfoque interdisciplinar. Primeramente, se analiza la evolución y distribución de las tasas de mortalidad, ponderando el impacto de la pandemia en el marco del proceso de transición sanitaria y analizando su distribución y grado de incidencia en relación con las características socioeconómicas de los distintos ámbitos espaciales de la provincia. En segundo lugar, y vinculado con este análisis sociodemográfico, se estudia el impacto de la pandemia sobre la actividad económica, así como las políticas públicas aplicadas y sus efectos en las principales haciendas públicas del territorio.

El análisis de Bizkaia guarda un especial interés por sus singulares características económicas e institucionales. Su posición como territorio neutral durante la Primera Guerra Mundial, industrializado, densamente poblado, espacialmente segregado y con una hacienda autónoma, la convierten en un caso de estudio idóneo y original para evaluar y analizar el impacto económico y social de la pandemia tanto en el ámbito público como privado.

El artículo plantea dos hipótesis iniciales. La primera, que aunque el virus fue ciertamente democrático en cuanto a su propagación, afectó de manera desigual a las poblaciones se- gún su condición socioeconómica y la densidad de población. La segunda hipótesis es que la pandemia no incidió de manera determinante en la evolución de la economía provincial -tanto en el sector privado como público-.

El artículo se sustenta en diversas fuentes de información. Desde el punto de vista demográfico, las dos principales fuentes empleadas son el Registro Civil (registros de defunciones y nacimientos) y el Boletín Mensual de Estadística Sanitaria de Bilbao (en adelante, Boletín Estadístico de Bilbao). A partir de los datos del primero se han reconstruido las tasas brutas de mortalidad $^{1}$. El Boletín Estadístico de Bilbao, por su parte, incluye información muy detallada y fiable en materia sanitaria y demográfica. Asimismo, se han consultado fuentes complementarias para profundizar en otras variables: el Movimiento $\mathrm{Na}$ tural de Población se ha empleado para estudiar las cifras generales de mortalidad de la provincia; el padrón municipal de habitantes de Bilbao de 1920 ha permitido diseccionar la estructura por edad y actividad económica de cada distrito de la ciudad. Además, también se ha recurrido a las cifras del Instituto Nacional de Estadística para calcular las tasas brutas de mortalidad.

El análisis presupuestario y contable para estudiar el impacto económico de la pandemia se ha basado en las actas, memorias y estadísticas empresariales, así como en la documentación oficial, actas y los presupuestos de las dos principales instituciones públicas del territorio: la Diputación de Bizkaia y el Ayuntamiento de Bilbao.

\section{Marco económico, institucional y poblacional de Bizkaia (1876-1930)}

El final de la última guerra carlista en el País Vasco (18721876) marcó el inicio de un periodo de hondas transformaciones en el territorio de Bizkaia. El proceso industrializador que venía madurando desde la primera mitad del siglo xIx despegó con vigor en el último cuarto de siglo. Para principios del siglo xx, Bizkaia sobresalía entre las provincias más industrializadas y prósperas del Estado. La capital, Bilbao, se transformó en una pujante metrópoli industrial, convirtiéndose en la principal plaza económica y financiera del norte de la Península. Este proceso de modernización propició una profunda transformación de la estructura económica, social, demográfica, política y urbanística del territorio (González Portilla, 2001).

Bajo el impulso de la industrialización, que se caracterizó por su alta concentración geográfica en torno a la ría de Bilbao, la población de Bizkaia aumentó de manera exponencial tanto por el crecimiento vegetativo como, especialmente, por la llegada masiva de inmigrantes de otras provincias españolas. La población del área de la ría de Bilbao se multiplicó por siete entre 1860 y 1930 (de 44302 a 304555 habitantes). En este mismo periodo, la población de Bilbao se multiplicó por nueve (de 17923 a 161978 habitantes). Como resultado, Bizkaia se convirtió en la provincia más densamente poblada de España. Esta alta densidad dota de un especial interés a este caso de estudio a la hora de analizar la propagación socioespacial de la enfermedad.

${ }^{1}$ Información proporcionada por la base de datos del Grupo de Investigación de Demografía Histórica e Historia Urbana de la UPV/EHU. 
Las políticas urbanísticas impulsadas para absorber este intenso crecimiento demográfico desembocaron en la conformación de un fragmentado escenario de segregación socioespacial (González Portilla, Hernando y Urrutikoetxea, 2018). Por un lado, la brecha económica y social entre el área metropolitana de Bilbao y el resto de la provincia se acentuó. A su vez, dentro del área de la ría de Bilbao la segregación espacial también se hizo evidente: mientras que el grueso de la población obrera se hacinó en los municipios mineros e industriales de la margen izquierda de la ría, la élite burguesa construyó sus núcleos residenciales en el ensanche de Bilbao o en la margen derecha, en municipios como Getxo.

Además, en el contexto del clientelar régimen de la Restauración, estas élites económicas ejercieron un control estricto sobre el poder de las instituciones públicas provinciales $\mathrm{y}$, en menor medida, municipales (Agirreazkuenaga y Alonso, 2014). Al amparo del Concierto Económico, las diputaciones vascas ejercían un amplio poder de autogobierno fiscal y financiero. Las élites económicas vizcaínas aprovecharon el control sobre la Diputación para establecer un marco institucional propicio para los intereses industriales y empresariales, liberando fiscalmente a los sectores productivos y aplicando una política de gastos centrada en priorizar el desarrollo económico (Alonso, 1997). No obstante, a partir del cambio de siglo, el modelo de hacienda y administración liberal experimentó un lento y gradual proceso de evolución hacía un incipiente modelo de Estado providencia. Esta intervención creciente de las Administraciones públicas en materia social fue clave para impulsar el proceso de transición sanitaria. Un ejemplo de ello fue la inauguración en $1908 \mathrm{del}$ moderno Hospital de Basurto impulsado por la Diputación de Bizkaia y el Ayuntamiento de Bilbao (González Portilla y Zarraga, 1998).

Del mismo modo, durante el primer tercio del siglo xx, en España, se sentaron las bases de un sistema de previsión social que promovió la implantación de los seguros sociales (Pons y Silvestre, 2010). Sin embargo, el seguro obligatorio de enfermedad no se implantó hasta 1942. Además, a excepción del seguro del retiro obrero, los seguros implantados antes de la II República tuvieron un carácter de libertad subsidiada, quedando subordinados a la capacidad de ahorro individual de cada trabajador. Las insuficiencias del sistema condicionaban por completo el margen de decisión de los trabajadores más humildes que no tenían capacidad de ahorro. Una contingencia laboral grave se podía convertir en un problema vital, especialmente para la clase obrera que dependía del jornal para subsistir. La política tradicional aplicada por las Administraciones públicas en momentos de crisis seguía basándose en el fomento de "obras públicas coyunturales, la beneficencia de los entes locales y las limosnas de los particulares» (Comín, 2010, p. 70).

Las tres primeras ondas de la gripe española coincidieron con el final de la Primera Guerra Mundial y la posterior crisis económica que sufrió Bizkaia fruto de la readaptación de su producción industrial tras el restablecimiento de la competencia en el mercado europeo. De la mano de la crisis económica y el aumento de precios, Bizkaia, y España en general, sufrieron un periodo de fuerte conflictividad laboral auspiciada por los movimientos obreros para reivindicar mejores condiciones salariales y sociales. Este estado de inestabilidad posbélico se prolongó hasta el golpe de Estado de Primo de Rivera de 1923.

\section{Salud pública y transición de la mortalidad}

El proceso de industrialización, el crecimiento urbanístico y demográfico descontrolado y la falta de condiciones de salubridad e higiene de las zonas urbanas provocaron graves problemas de salud en los núcleos industriales de Europa durante el siglo xix. Bizkaia no fue una excepción.

En el último cuarto del siglo xIx, la mayoría de municipios del área de la ría de Bilbao se expandieron sin planificación ni equipamientos básicos suficientes para afrontar el incremento demográfico (Arbaiza, 1999). El hacinamiento, la insalubridad y las carencias alimentarias fueron un denominador común en la mayor parte de la ría, especialmente en los municipios mineros. Por este motivo, el área urbana de la ría de Bilbao fue un foco de difusión de enfermedades infectocontagiosas, incluidas las epidemias gripales.

Epidemiológicamente, el siglo xix estuvo marcado por sucesivas pandemias de cólera que empujaron a tomar medidas de salud pública. Bilbao sufrió cuatro graves episodios de cólera: $1834,1854,1885$ y 1894 (Vitoria, 1978, p. 9). El de 1854 provocó el fallecimiento del $4 \%$ de sus habitantes (Nadal, 1986, p. 148). Las epidemias de cólera impulsaron la higienización de la ciudad al abordar obras de gran envergadura como el sistema de saneamiento, la construcción de depósitos y traídas de aguas y múltiples iniciativas análogas en el terreno sanitario (Gondra y Erkoreka, 2010).

El segundo gran problema sanitario de la segunda mitad del siglo xix y las primeras décadas del siglo xx fue la tuberculosis, que provocó la muerte de 5 por cada 1000 habitantes y año en la sociedad finisecular bilbaína (Villanueva, 1985).

Además de estas dos enfermedades bacterianas y de otras patologías extendidas, a finales del siglo xix comenzaron a tomar protagonismo las pandemias víricas como la gripe. La aparición de la pandemia de gripe de 1889-1890 abrió un nuevo escenario médico. Iniciada en 1889 , la conocida como gripe rusa alcanzó su cénit en 1890 al provocar una tasa de mortalidad en Europa Occidental que osciló entre el 1 y el 2,8 por 1000 habitantes (Valleron, Cori y Valtat, 2010).

La evolución en forma de dientes de sierra de la tasa bruta de mortalidad en el último cuarto del siglo xix en el área de la ría de Bilbao es un reflejo de la cotidianeidad con la que se enfrentó la sociedad de la época a estos episodios epidemiológicos y pandémicos:

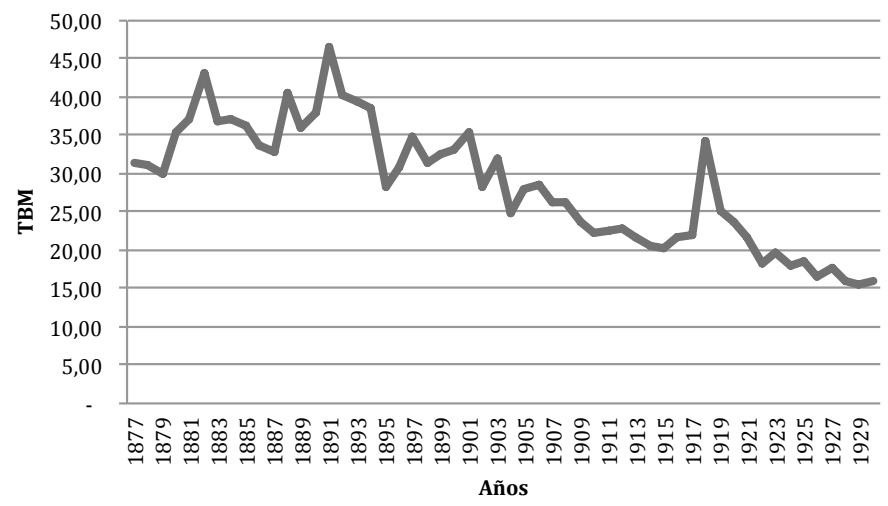

Figura 1. Tasa Bruta de Mortalidad (TBM) en el Área Metropolitana de la ría de Bilbao (1877-1930).

Fuente: Registro Civil e INE. 
A partir del salto de siglo, la tendencia de la tasa de mortalidad se moduló. Desde comienzos del siglo xx las tasas brutas de mortalidad comenzaron a reducirse y estabilizarse. Los picos de mortalidad que producían a finales del siglo xix enfermedades como el cólera, la viruela, el sarampión, etc. comenzaron a controlarse, dando lugar a una reducción de las tasas brutas de mortalidad. Este control de la mortalidad hay que relacionarlo con una serie de variables y políticas públicas que, con distinta intensidad, se repitieron en toda España (Pérez, Reher y Sanz, 2015).

Centrándonos en Bizkaia, en primer lugar, la presión demográfica se relajó debido a la moderación en el crecimiento de la población. En segundo lugar, los ayuntamientos realizaron importantes inversiones para dotar de mejores infraestructuras higiénicas a los núcleos urbanos. Asimismo, también se incrementó la inversión pública para modernizar la red sanitaria vizcaína y adaptarla a las necesidades y avances científicos del momento (Pérez Castroviejo, 2002). La Diputación de Bizkaia y los ayuntamientos aumentaron paulatinamente su inversión en gasto sanitario durante las primeras tres décadas del siglo xx para completar y perfeccionar la red sanitaria y asistencial (Roda, 1931). Otros factores como la inversión en educación o los avances en materia alimentaria también mejoraron las condiciones generales de salud (Bernabeu-Mestre et al., 2016).

Como resultado de la transición sanitaria y del resto de factores y políticas conducentes a mejorar las condiciones de vida generales de la población, Bizkaia experimentó un proceso de transición de la mortalidad a partir de principios del siglo xx. La transición de la mortalidad fue una revolución en materia demográfica al propiciar una disminución de las tasas brutas de mortalidad (especialmente infantil y juvenil), lo que influyó determinantemente en el aumento notable de la esperanza de vida al nacer.

El análisis de la pandemia de gripe española se reviste de un especial interés por el momento en el que se produjo, en pleno proceso de transición de la mortalidad, sobresaliendo como un accidente dentro de la tendencia descendente en la evolución de las tasas brutas de mortalidad. Como se puede apreciar en la figura 1, aunque desde una perspectiva temporal más amplia no resulte tan excepcional, la gripe española supuso un repunte sinuoso de la mortalidad que sorprendió en cierta manera a la sociedad de principios del siglo xx, que parecía haber dejado atrás este tipo de episodios (Echeverri, 1993).

\section{La incidencia de la pandemia de gripe española en Bizkaia: propagación y distribución espacial}

Coincidiendo con los movimientos de tropas a nivel mundial y las inhumanas condiciones en las que se venía desarrollando la Primera Guerra Mundial desde 1914, en los primeros meses de 1918 miles de soldados de múltiples nacionalidades padecieron una epidemia de gripe. En Francia, según la documentación de los Archives du Services de Santé des Armée, enfermaron de influenza 1850 soldados americanos durante el mes de abril, sin contabilizar fallecidos. En mayo, esta epidemia de gripe se extendía en casi toda Europa, y ocurrió un importante episodio en Madrid (Porras, 1997). En esta ciudad, según el Boletín de Estadística Municipal de Madrid, la tasa de mortalidad por gripe y complicaciones respiratorias fue de 1,0 por 1000 habitantes entre mayo y julio de 1918. Si hacemos una búsqueda más selectiva y fiable del exceso de mortalidad en la ciudad en estas fechas, la cifra se eleva hasta 1,7 por 1000 habitantes (Erkoreka, 2017). En Bilbao, tomando los datos del Boletín Estadístico de Bilbao, el exceso de mortalidad achacable a la gripe y sus complicaciones ascendió a 0,6 por 1000 habitantes en primavera (Gondra y Erkoreka, 2010, p. 150).

La epidemia desapareció en verano, pero el virus mutó y a partir de septiembre estalló la segunda onda de una manera simultánea en todo el hemisferio norte. En tres meses, esta segunda onda mató a cuarenta millones de personas en todo el mundo, sobre todo adultos jóvenes entre 15 y 34 años (Erkoreka, 2010). En Europa mató el 1,1\% de su población, siendo este exceso de mortalidad más alto en los países del sur (Italia 15,1 por 1000 y España 12,0 por 1000) y más bajo en el norte (Finlandia 7,4 por 1000 y Noruega 5,6 por 1000 habitantes) (Ansart et al., 2009).

En España, uno de los puntos por los que se propagó la onda otoñal fue el nudo de comunicación que constituyen Irun y Hendaya, en la frontera franco-española. La epidemia fue tan violenta que entre septiembre y octubre mató al $1 \%$ de la población de Irún, y afectando de igual manera a otros pueblos próximos de Gipuzkoa y de Navarra. Para el mes de octubre estaba ya presente en toda España, y provocó hasta abril de 1919 un exceso de mortalidad de 9,2 fallecidos por cada 1000 habitantes. Las diferencias de mortalidad entre unas provincias $\mathrm{y}$ otras fueron muy pronunciadas. Mientras que el exceso de mortalidad atribuible a la pandemia se situó por encima de 16 por 1000 habitantes en Burgos y Almería, en provincias como Sevilla, Málaga y Madrid osciló entre 2,9 y 3,7 fallecidos por 1000 habitantes (Chowell et al., 2014).

Centrándonos en Bizkaia, la cronología de las cuatro ondas pandémicas fue la siguiente: una onda de leve intensidad en primavera de 1918; la onda más grave entre septiembre y diciembre de 1918; una tercera onda de menor intensidad entre enero y mayo de 1919, y una última onda con mucha menor incidencia en el primer trimestre de 1920 (Erkoreka, 2006). El artículo se centrará en el periodo que abarcan la segunda y la tercera onda -el último cuatrimestre de 1918 y el primero de 1919-, la fase de mayor incidencia del virus.

Respondiendo a uno de los objetivos de la presente investigación, primeramente se analizará el nivel de afección del virus en tres ámbitos espaciales delimitados según sus características socioeconómicas, demográficas y urbanísticas: Bilbao, el área metropolitana de la ría de Bilbao y el resto de la provincia.

El área metropolitana de la ría está compuesta por trece municipios, incluido Bilbao, y representaba el $60,1 \%$ de la población total de la provincia en 1920 (Bizkaia tenía 409550 habitantes). Esta área constituía el hinterland de la provincia donde se concentraba la industria. Para el estudio de la ría de Bilbao se han analizado los registros civiles de once municipios: Bilbao, Baracaldo, Sestao, Portugalete, Santurtzi, Ortuella, Galdames, Basauri, Leioa, San Salvador del Valle y Abanto y Zierbena ${ }^{2}$. Por tanto, se han analizado las series de mortalidad completas correspondientes al $92 \%$ de la población del área metropolitana. El resto de la provincia, que reunía el $39,9 \%$ restante de la población, se componía principalmente de municipios pequeños o medianos que en contadas ocasiones superaban los 5000 habitantes y cuya actividad económica seguía estando mayormente vinculada al sector primario (González Portilla, Hernando y Urrutikoetxea, 2018).

\footnotetext{
${ }^{2}$ Por ausencia de registros informatizados faltan los datos de Erandio y Getxo.
} 
Basándonos en las series de mortalidad y los registros de defunciones de los registros civiles de los municipios, en la figura 2 se muestra gráficamente la evolución de las tasas brutas de mortalidad en los tres ámbitos espaciales.

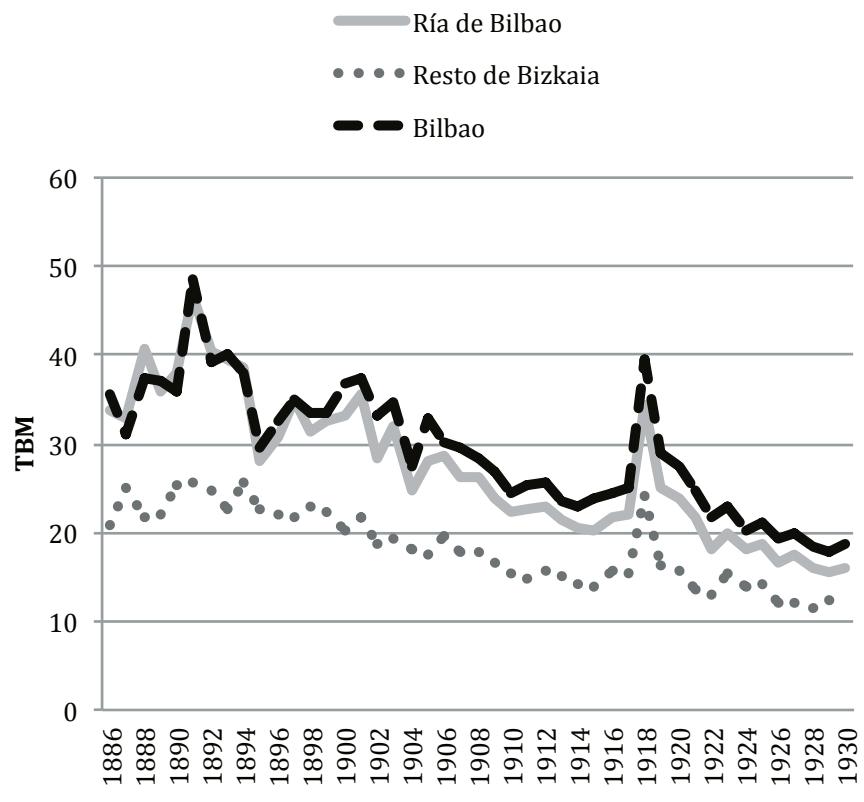

Años

Figura 2. Tasa Bruta de Mortalidad (TBM) en Bilbao, el Área Metropolitana de la Ría de Bilbao y el resto de Bizkaia (1886-1930).

Fuente: Registro Civil, MNP e INE.

Bilbao y el área metropolitana sufrieron una mayor mortalidad en comparación con la zona rural y costera durante todo el periodo analizado. En esta zona, las tasas brutas de mortalidad se mantuvieron por debajo de las cifras de la zona industrial.

El área metropolitana de la ría de Bilbao vio incrementadas sus tasas brutas de mortalidad en un 12,3 por 1000 habitantes por la pandemia (pasó de un 21,9 por 1000 en 1917 a un 34,3 por 1000 en 1918). El impacto en la mortalidad fue mayor en los municipios de carácter más industrial, apreciándose una relación entre el tamaño y la densidad de población y la incidencia de la pandemia. Bilbao, Sestao y Baracaldo, las tres ciudades más pobladas, sufrieron las mayores tasas de mortalidad.

La gripe española también se hizo notar en el resto de la provincia. De promedio, los 105 municipios de menor tamaño analizados incrementaron su tasa bruta de mortalidad en un 8,6 por 1000 (pasando de un 15,4 por 1000 en 1917 a un 24,0 por 1000 en 1918). El aumento de las tasas brutas de mortalidad por la pandemia fue significativamente más alto en el área metropolitana que en el resto de la provincia.

Por lo tanto, cabe concluir que aspectos ligados a la industrialización, el hacinamiento o los déficits higiénicos fueron factores determinantes en la propagación de la pandemia. La relación causal, en este caso, fue directamente proporcional: a mayor tamaño y densidad de población, mayor incidencia de la pandemia.

Tras desarrollar la comparativa a nivel provincial para contraponer el impacto de la gripe entre el área metropolitana y el resto de la provincia, a continuación pondremos el foco en el ámbito urbano, analizando el caso de la capital. Bilbao era el centro económico y la ciudad más poblada de la provincia con 112819 habitantes en 1920. Gracias al Boletín Estadístico de Bilbao contamos con detalladas estadísticas mensuales de mortalidad por distritos. Estas estadísticas y la pronunciada estratificación socioeconómica de los distritos permiten analizar la correlación entre el grado de incidencia de la pandemia y las desigualdades sociales por distritos.

La tasa de mortalidad de la pandemia alcanzó el 0,6 por 1000 habitantes en la primera onda de primavera de 1918. La segunda onda, la más grave, afectó a la ciudad entre septiembre y diciembre. El mes de septiembre fallecieron diagnosticados de "grippe» 8 personas; en octubre 480; en noviembre 146, y en diciembre 16. Si a estas cifras le sumamos los fallecidos por las principales complicaciones de la gripe -la neumonía y la bronconeumonía-, en este lapso de tiempo de cuatro meses fallecieron un total de 869 personas. Es decir, la tasa bruta de mortalidad imputada a la pandemia fue de 8,4 por 1000 habitantes. Estas cifras son aún mayores si analizamos el exceso de mortalidad; es decir, todas las defunciones producidas por encima de la media de los años anteriores. Esta segunda onda remitió para diciembre de 1918, y rebrotó en forma de tercera onda entre enero y mayo de 1919. La tercera onda, de menor intensidad, mató a 329 personas en Bilbao, lo que supuso una tasa bruta de mortalidad de 3,1 por 1000 habitantes. En verano el virus dejó de circular y no volvió a aparecer hasta el primer trimestre de 1920, ocasionando el fallecimiento de 247 personas en Bilbao y alcanzando una tasa de mortalidad de 2,2 por 1000 habitantes.

Además de la tasa de mortalidad, también hay que tener en cuenta las altas tasas de morbilidad que produjo la gripe. Aunque en la época no se elaboraron estadísticas pormenorizadas de morbilidad, se estima que aproximadamente la mitad de la población de Bizkaia padeció la gripe (Gondra y Erkoreka, 2010, p. 152).

Una de las principales características de esta pandemia fue que afectó fundamentalmente a adultos jóvenes. Concentrándonos en los efectos de la segunda onda, la más letal, los grupos de edad de 20-39 años fueron los que presentaron más defunciones a causa de la gripe: una población que representaba el $33 \%$ del total de la ciudad concentró un 38\% de las defunciones por gripe. Otro pico significativo de fallecidos fueron los menores de 10 años. Una población que representaba un $20 \%$ de los habitantes totales presentó un $26 \%$ del exceso de defunciones totales ${ }^{3}$.

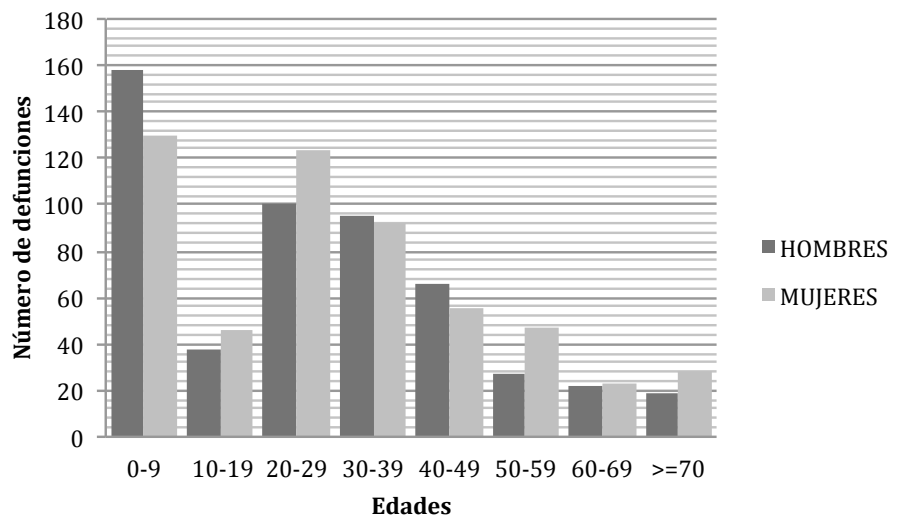

Figura 3. Defunciones por la gripe española en Bilbao por grupos de edad en 1918. Fuente: Boletín Mensual de Estadística Sanitaria de Bilbao, 1918.

\footnotetext{
${ }^{3}$ Calculado a partir del padrón municipal de habitantes de Bilbao de 1920.
} 
En cuanto a la distribución de la mortalidad por distritos, se aprecian ciertas diferencias según el estrato social de cada zona. Partiendo del análisis del padrón municipal de 1920, el mapa urbano de Bilbao reflejaba una clara segregación espacial por distritos según las condiciones socioeconómicas de sus habitantes. Primeramente, presentaba tres distritos de concentración de clase obrera (mayormente empleados industriales de baja cualificación): Cortes, Achuri y Bilbao la Vieja. Los jornaleros sin cualificación ascendían al 69,13\% de los cabeza de familia del distrito de Cortes, un 72,75\% en Bilbao la Vieja, y un $57,7 \%$ del distrito de Atxuri. En segundo lugar, cabría identificar cuatro distritos con mayor diversidad y heterogeneidad donde convivían trabajadores sin cualificar con grupos que podríamos calificar como clases medias (por ejemplo, comerciantes o profesionales liberales): San Francisco, Estación, Casas Consistoriales y Santiago. Estos cuatro distritos presentaban un porcentaje de cabezas de familias jornaleras inferior al 30\% en todos los casos, a excepción de San Francisco, donde se alcanzaba una cifra del 46,1\%. También existía un distrito ciertamente singular, el de Hospital, que como su nombre indica se correspondía con la zona del Hospital de Basurto, incluyendo una pequeña parte del ensanche (zona San Mamés) y algunos barrios de elevada concentración obrera (Zorroza, Castrejana). De ahí la elevada concentración obrera del distrito, con un $71,3 \%$ de familias obreras. Por último, las clases más altas se concentraban en el ensanche, en los distritos de San Vicente y Gran Vía. En ambos distritos los cabeza de familia jornaleros representaban el 27,1\% del total.

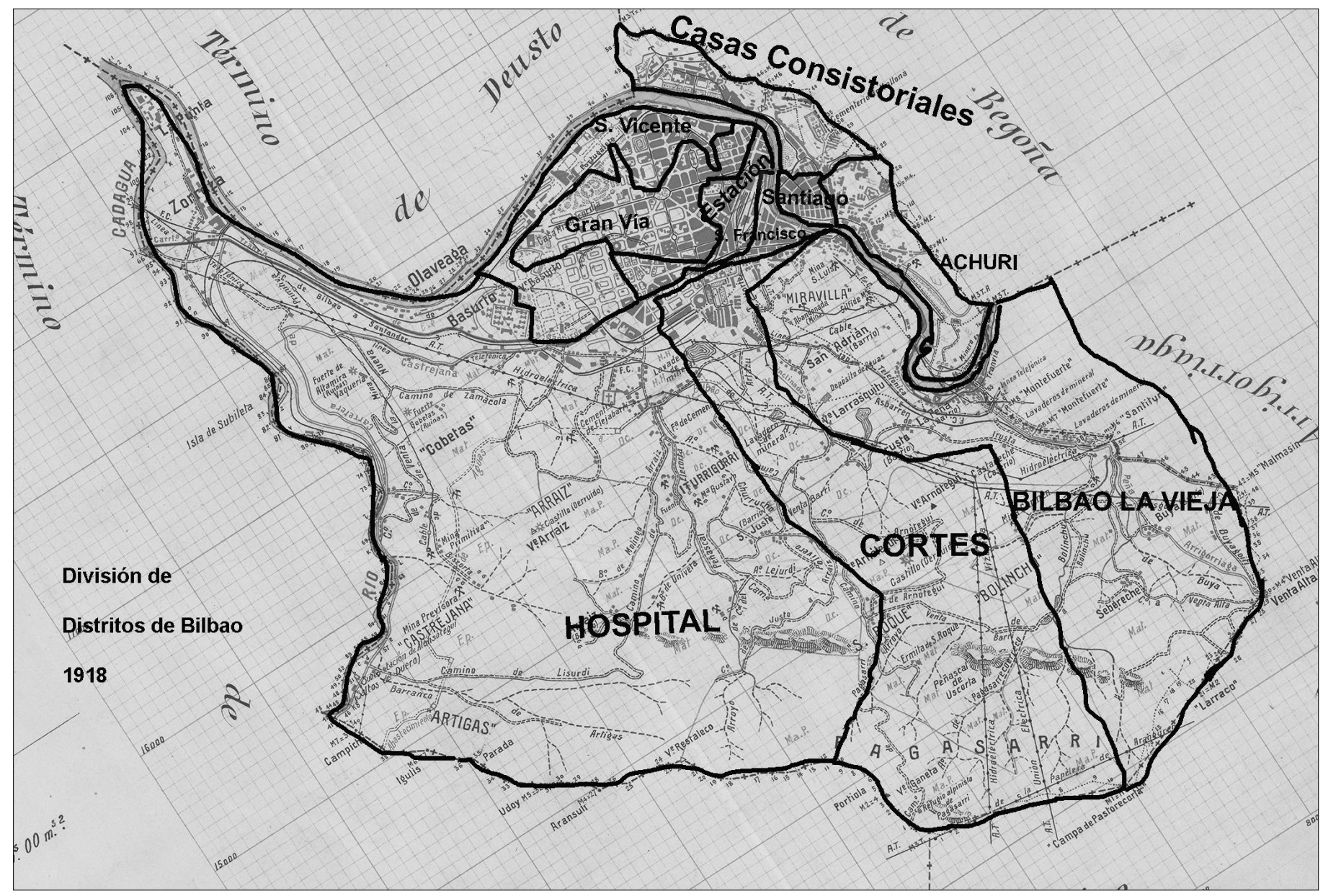

Figura 4. Mapa de Bilbao por distritos (1918).

Fuente: elaboración propia.

La pandemia afectó en todos los distritos de la ciudad, pero con desigual intensidad: además del distrito Hospital (distorsionado por la presencia del hospital y la Casa de Misericordia), los tres distritos obreros sufrieron las mayores tasas brutas de mortalidad (con cifras comprendidas entre el 32 y 39 por 1000 habitantes). Estos mismos distritos son los que más aumentaron sus tasas de un año a otro como consecuencia de la pandemia. En el extremo opuesto, el ensanche bilbaíno, zona de residencia de la burguesía, presentó las tasas de mortalidad más reducidas (San Vicente un 24,33 por 1000 y Gran Vía un 20,79 por 1000).
Los motivos de esta diferencia por zonas en una ciudad de tamaño reducido $\left(41 \mathrm{~km}^{2}\right)$ son varios, pudiendo destacarse dos factores. Por un lado, la concentración espacial. Aunque todos los distritos presentan una población similar cercana a los 10000 habitantes, en los distritos obreros las viviendas se concentraban en espacios más reducidos, aspecto que se agravaba por una elevada cohabitación de diferentes núcleos familiares en una misma vivienda, tal y como se aprecia en el padrón de 1920. En el ensanche los espacios eran mayores, la planificación urbana mejor y se disponía de un mayor número de habitacio- 
nes y estancias por familia. Por otro lado, el ensanche contaba con un sistema de tratamiento de aguas y condiciones de salubridad mejores que los barrios obreros (Novo y Zarraga, 2019).

A continuación, se puede apreciar la incidencia de la pandemia por distritos a través de la comparación de los años 1917 y 1918:

\section{Tabla 1}

Tasas brutas de mortalidad por 1000 habitantes en Bilbao por distritos $(1917-1918)^{4}$

\begin{tabular}{|lrrr|}
\multicolumn{1}{c}{ Distrito } & $\mathbf{1 9 1 7}$ & $\mathbf{1 9 1 8}$ & Incremento \\
\hline Cortes & 25,88 & 38,37 & 12,49 \\
\hline Hospital & 17,28 & 37,22 & 19,94 \\
\hline Bilbao La Vieja & 22,21 & 36,80 & 14,59 \\
\hline Achuri & 17,77 & 32,15 & 14,38 \\
\hline San Francisco & 23,28 & 29,69 & 6,41 \\
\hline Casas Consistoriales & 17,92 & 28,35 & 10,43 \\
\hline Santiago & 19,26 & 27,93 & 8,67 \\
\hline Estación & 16,15 & 27,86 & 11,71 \\
\hline San Vicente & 22,43 & 24,33 & 1,90 \\
\hline Gran Vía & 9,89 & 20,79 & 10,90 \\
\hline
\end{tabular}

Fuente: Boletín Mensual de Estadística Sanitaria de Bilbao, 1917 y 1918.

\section{El impacto de la pandemia en la actividad económica}

Como se ha analizado en el apartado anterior, la pandemia tuvo una importante incidencia sobre los adultos jóvenes en edades comprendidas entre 20 y 39 años. Es decir, afectó preferentemente al núcleo de la población activa, provocando el fallecimiento en algunos casos y una larga temporada de convalecencia en otros. Teniendo en cuenta las características y el desarrollo de la pandemia, habría que responder a dos preguntas: ¿en qué grado afectó la pandemia al desarrollo de la actividad y los rendimientos empresariales? Y, en segundo lugar, ¿la pandemia fue un factor añadido en la crisis económica y la conflictividad laboral posbélica? Estas cuestiones son difíciles de contestar de forma precisa, puesto que los resultados de las empresas dependen de muchas variables. La dificultad reside en aislar los efectos de la pandemia de otros condicionantes coyunturales como la subida de los precios o la adaptación de la producción en el escenario posbélico.

El pico de la onda más intensa, en otoño de 1918, coincidió con el final de la Primera Guerra Mundial. Aunque España fuera neutral en el conflicto, experimentó unas acusadas consecuencias económicas, sociales y políticas (Fuentes y García, 2015). El esfuerzo de guerra de las economías beligerantes dejó sin competencia a empresas de países neutrales. Durante los años de la Primera Guerra Mundial, los beneficios de las sociedades anónimas vizcaínas reportaron una rentabilidad media que fue desde un 6\% en 1914 hasta un máximo de un 33\% en 1918 (Alonso, 1997).

\footnotetext{
${ }^{4}$ Las tasas brutas de mortalidad (TBM) se han calculado en este caso sin tener en cuenta forasteros y acogidos en establecimientos benéficos para que la comparativa entre distritos no se distorsione. Por este motivo, la TBM bilbaína general es aún mayor.
}

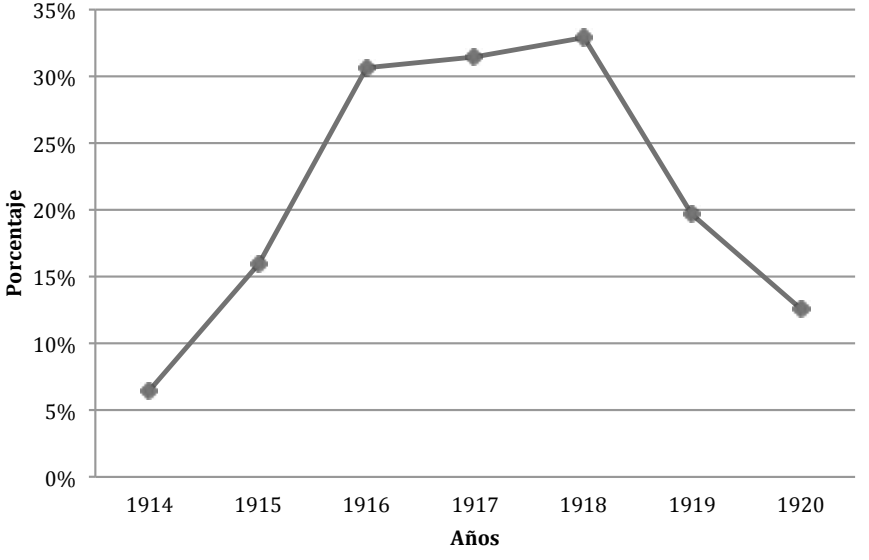

Figura 5. Rentabilidad de las sociedades anónimas domiciliadas en Bizkaia (1914-1920). La rentabilidad se calcula como proporción de los beneficios sobre el capital desembolsado más reservas.

Fuente: Liquidaciones de la Tarifa 3. e de Utilidades. AHFB: Administrativo, Hacienda, Utilidades, cajas 420 a 545.

Los beneficios, sin embargo, no se repartieron por igual en todos los sectores. Hubo algunos, como el naviero o siderometalúrgico, que vivieron un enorme repunte, mientras que en otros el aumento fue más modesto.

El récord lo marcaron el sector siderometalúrgico con un $120 \%$ en 1917 y el naviero con un 104\% en 1916. En el caso de las navieras, las ganancias procedieron tanto del negocio del flete como de la liquidación de sociedades tras vender sus buques a precios desorbitados. Por ejemplo, la Naviera Olazarri, que entró en liquidación en 1917, vendió sus buques a la Naviera Blanca, obteniendo unos beneficios de casi dieciocho millones de pesetas (con un capital de cuatro millones). Fruto de esta operación, la Diputación recaudó casi 700000 pesetas por utilidades, cantidad con la que cubría casi completamente el presupuesto para ese año en Instrucción Pública o que suponía el doble de lo consignado a los hospitales de la provincia.

Gracias a la neutralidad española, la economía vizcaína experimentó un periodo expansivo, cuyo pico en forma de beneficios se alcanzó en el ejercicio de 1918. La aparición de la pandemia coincidió con el inicio del restablecimiento de la competencia en el mercado europeo, teniendo que adaptar la producción al nuevo escenario. Aunque no se puede hacer un cuadro completo de cómo afecto la pandemia en esta especial coyuntura, sí tenemos algunos indicios de interés que nos pueden mostrar los efectos de la misma en algunas empresas.

Por ejemplo, en la empresa Santa Ana de Bolueta, la gripe afectó a un gran número de obreros (Alonso, Erro y Arana, 2016). Para evitar los efectos de las inasistencias al trabajo, la empresa decidió pagar a los enfermos la mitad del jornal mientras durase su postración. En los cuatro casos de fallecimiento -sobre unos doscientos obreros- pagaron a las viudas una mensualidad y 100 pesetas como gratificación ${ }^{5}$. Además, la empresa aportó 500 pesetas a la suscripción abierta por el Ayuntamiento de Begoña para luchar contra la enfermedad. Para ponderar el alcance de estos desembolsos cabe citar que ese año la empresa obtuvo unos beneficios líquidos cercanos a las 500000 pesetas.

\footnotetext{
${ }^{5}$ Libro de actas de Santa Ana de Bolueta, 29/10/1918, AHFB.
} 
Tabla 2

Rentabilidad de las sociedades anónimas domiciliadas en Bizkaia por sectores (1914-1921).

\begin{tabular}{|c|c|c|c|c|c|c|c|c|}
\hline & 1914 & 1915 & 1916 & 1917 & 1918 & 1919 & 1920 & 1921 \\
\hline Bancos & $10 \%$ & $10 \%$ & $12 \%$ & $21 \%$ & $32 \%$ & $22 \%$ & $10 \%$ & $10 \%$ \\
\hline Navieras & $8 \%$ & $68 \%$ & $104 \%$ & $67 \%$ & $68 \%$ & $34 \%$ & $16 \%$ & $4 \%$ \\
\hline Siderometalúrgicas & $12 \%$ & $14 \%$ & $17 \%$ & $120 \%$ & $17 \%$ & $12 \%$ & $19 \%$ & $9 \%$ \\
\hline Químicas, papeleras y cementos & $3 \%$ & $2 \%$ & $9 \%$ & $14 \%$ & $15 \%$ & $12 \%$ & $17 \%$ & $14 \%$ \\
\hline Servicios & $5 \%$ & $4 \%$ & $5 \%$ & $4 \%$ & $9 \%$ & $7 \%$ & $3 \%$ & $5 \%$ \\
\hline Bienes equipo & $4 \%$ & $7 \%$ & $10 \%$ & $18 \%$ & $14 \%$ & $6 \%$ & $8 \%$ & $6 \%$ \\
\hline Constructoras e inmobiliarias & $4 \%$ & $1 \%$ & $2 \%$ & $3 \%$ & $10 \%$ & $7 \%$ & $5 \%$ & $10 \%$ \\
\hline Alimentación & $6 \%$ & $7 \%$ & $11 \%$ & $8 \%$ & $15 \%$ & $12 \%$ & $9 \%$ & $9 \%$ \\
\hline Transportes & $4 \%$ & $5 \%$ & $5 \%$ & $6 \%$ & $6 \%$ & $8 \%$ & $8 \%$ & $7 \%$ \\
\hline Eléctricas & $7 \%$ & $7 \%$ & $7 \%$ & $8 \%$ & $9 \%$ & $9 \%$ & $10 \%$ & $10 \%$ \\
\hline Textiles & $2 \%$ & $5 \%$ & $6 \%$ & $12 \%$ & $0 \%$ & $9 \%$ & $15 \%$ & $0 \%$ \\
\hline Mineras y canteras & $2 \%$ & $4 \%$ & $6 \%$ & $10 \%$ & $18 \%$ & $18 \%$ & $3 \%$ & $1 \%$ \\
\hline Astilleros & $2 \%$ & $2 \%$ & $3 \%$ & $5 \%$ & $14 \%$ & $7 \%$ & $14 \%$ & $15 \%$ \\
\hline Artes gráficas & $0 \%$ & $0 \%$ & $0 \%$ & $0 \%$ & $0 \%$ & $0 \%$ & $0 \%$ & $4 \%$ \\
\hline Varios & $7 \%$ & $11 \%$ & $12 \%$ & $7 \%$ & $31 \%$ & $37 \%$ & $8 \%$ & $15 \%$ \\
\hline Total & $6 \%$ & $16 \%$ & $31 \%$ & $31 \%$ & $33 \%$ & $20 \%$ & $13 \%$ & $8 \%$ \\
\hline
\end{tabular}

Fuente: îd. figura 5.

Otra fuente en la que se podría ver el efecto de la gripe es la documentación de la Mutua Patronal de Accidentes de Trabajo de Vizcaya. Sin embargo, no encontramos rastros directos en su actividad por dos motivos. El primero, porque atendía a los accidentes de trabajo, no a las bajas por enfermedad. En segundo lugar, las fuentes de la empresa se limitan a ofrecer resultados anuales. La referencia más llamativa, y que tenga que ver con la pandemia, está en la memoria de 1918, en la que se reconoce que recibieron fuertes presiones de los patronos debido a la falta de obreros de oficio para asegurar a obreros herniados, "teniendo en cuenta además la existencia de un número considerable de obreros que por su estado de salud no se les podía aconsejar la operación de hernia sin cometer una imprudencia» (Sociedad de Seguros Mutuos de Vizcaya sobre accidentes de Trabajo, 1919, p. 9). El efecto de la gripe se puede deducir por la fecha del acuerdo de la Junta Directiva, que en su reunión del 28 de septiembre acordó admitir al seguro a los obreros herniados con la única excepción de los ya indemnizados (Alonso, 2000).

En las memorias anuales de 1918, 1919 y 1920 de dos de las principales empresas de Bizkaia, Altos Hornos de Vizcaya y el Banco de Bilbao, no se localiza ninguna referencia a la pandemia. Del mismo modo, las memorias anuales de 1918 y 1919 de la Cámara de Comercio de Bilbao, así como su revista quincenal, Información: Órgano Oficial de la Cámara de Comercio de Bilbao, tampoco realizan mención alguna sobre la pandemia o la escasez de mano de obra.

De la muestra de fuentes analizada se deduce que en el contexto de adaptación a la baja de la producción que se produjo tras el final de la guerra, el sector empresarial no sufrió de manera determinante las consecuencias de la pandemia sobre la oferta de mano de obra.
Centrándonos en la clase trabajadora, durante este periodo sufrió el doble golpe de la pandemia, por un lado, y los efectos del final de la guerra sobre el mercado laboral y los precios por el otro. En relación con la enfermedad, la insuficiencia de los mecanismos de protección social condicionaron el margen de acción de los trabajadores con menor capacidad de ahorro. Las familias más humildes padecieron dificultades para prescindir del jornal del cabeza de familia, especialmente en los casos en los que el plazo de convalecencia se alargaba. Esta cuestión fue debatida en el pleno de la Diputación del 8 de noviembre de 1918 como un factor clave a la hora de controlar la enfermedad ${ }^{6}$ :

Al atacar la enfermedad al cabeza de familia toda esta a de sufrir necesariamente privaciones. [...]. La misma necesidad obliga a los enfermos a salir de casa antes de tiempo y generalmente recaen y en la mayoría de los casos la recaída es por la enfermedad. Los médicos rurales aseguran que muchas de las víctimas de la enfermedad se deben a la falta de recursos en las familias, lo que es causa de que muchas madres envíen a sus hijos a la calle y otras personas salen cuando no se hallan en condiciones para ello y por eso se hace de todo punto necesario acudir en auxilio de quienes carecen de recursos para evitar en lo posible que siga causando víctimas la epidemia.

Algunas empresas, como Santa Ana de Bolueta, asumieron la cobertura a los empleados enfermos con sus propios medios. Altos Hornos de Vizcaya también tenía su propio sistema de previsión para cubrir este tipo de contingencias. Pero

\footnotetext{
${ }^{6}$ Las referencias sobre la actuación de la Diputación en esta sección y la siguiente proceden de las Actas de la Comisión Provincial y de las Actas del pleno de la Diputación de 1918 y 1919, AHFB.
} 
como veremos a continuación, en los casos en los que las empresas no acudieron a sostener a los empleados enfermos la provisión de los recursos básicos para la subsistencia de las familias desamparadas recayó sobre las Administraciones públicas.

\section{La huella de la pandemia en la hacienda pública vizcaína}

Además de responder ante la crisis sanitaria, las instituciones públicas tuvieron que enfrentarse a la crisis social derivada de las necesidades que produjo la pandemia en las familias más humildes. Dentro del marco institucional de la época, las funciones asistenciales correspondían mayormente a las diputaciones y ayuntamientos. Es por ello que el análisis se centrará en el papel que desempeñaron la Diputación de Bizkaia y el Ayuntamiento de Bilbao. Aunque en los archivos de ambas instituciones no se han localizado las liquidaciones presupuestarias del ejercicio de 1918, las actas y la documentación oficial permiten reconstruir la huella de la pandemia tanto en la parte del ingreso como del gasto.

Enlazando con el apartado anterior, el incremento extraordinario de los beneficios empresariales durante la guerra también se reflejó en un aumento recíproco de la recaudación de las Administraciones públicas vizcaínas gracias al Concierto Económico. Al amparo del Concierto Económico, las diputaciones vascas gozaban de una amplia autonomía fiscal para regular sus respectivos sistemas impositivos en todo lo que a los impuestos concertados se refería (Erkoreka M., 2018). Entre otros, gestionaban la tarifa del impuesto de utilidades, que gravaba los beneficios empresariales, las contribuciones industrial y territorial y el impuesto sobre consumos. Como contrapartida, tenían la obligación de financiar las arcas de la hacienda central vía cupo. La diferencia entre la recaudación total y el pago del cupo al Estado, quedaba en poder de las diputaciones en forma de autonomía financiera, permitiéndoles desarrollar una política de gastos propia no dependiente de las transferencias del Estado (Alonso, 1995).

Además, dado que las diputaciones vascas ejercían la tutela financiera de las haciendas municipales, los ayuntamientos también gozaban de una mayor autonomía financiera que sus homólogas de régimen común. Esta capacidad de autogobierno fiscal explica en buena medida el mayor desarrollo que alcanzaron en general las infraestructuras y los servicios públicos en el País Vasco en comparación con otras provincias, incluidas las ramas de la beneficencia y sanidad (Erkoreka M., 2017).

La última renovación del cupo antes del inicio de la Primera Guerra Mundial se acordó en 1906 para veinte años. El acuerdo estableció un cupo anual para pagar por las tres diputaciones de 8577899,32 de pesetas, de cuyo total a Bizkaia le correspondían 4942933,75 pesetas. En aquella época, el cupo tenía un carácter fijo, cuya cuantía se mantenía inamovible entre renovación y renovación. El cupo no se ajustaba a los ciclos económicos ni variaba dependiendo de las oscilaciones en la recaudación. Por tanto, el aumento de la recaudación por el impuesto de utilidades que gravó los ingentes beneficios empresariales cosechados durante los años de la guerra, fue a parar de manera íntegra a las arcas de la Diputación, reforzando su autonomía financiera:

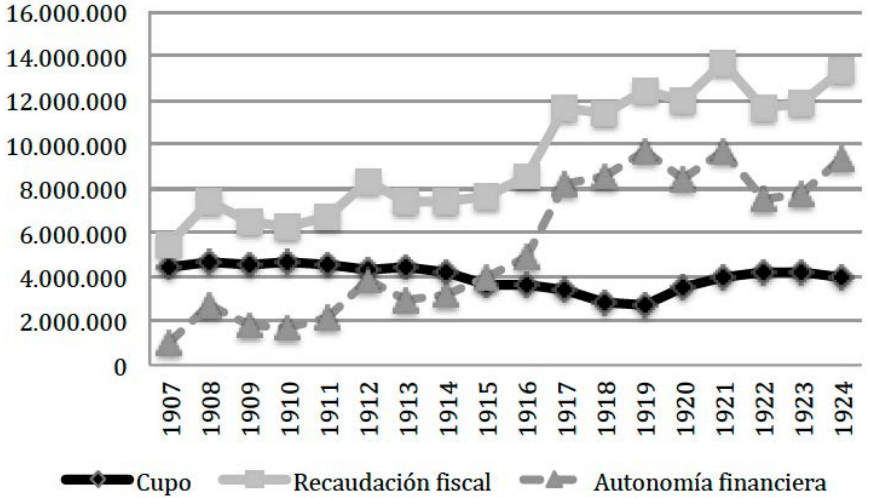

Figura 6. Evolución de la autonomía financiera (recaudación fiscal - cupo) de la Diputación de Bizkaia (1907-1924) (en pesetas constantes de 1913).

Fuente: AHFB, estadísticas de recaudación.

En mayo de 1918, Ramón de la Sota, presidente de la Diputación, describió «la situación económica de la Diputación» como «brillante» ${ }^{7}$. Así pues, la Diputación afrontó la pandemia en una situación de holgura financiera. El Ayuntamiento de Bilbao también se benefició de la buena marcha de la economía durante los años de la guerra ${ }^{8}$. Resumiendo, la pandemia golpeó a las instituciones públicas vizcaínas en una coyuntura expansiva, especialmente próspera en el caso de la Diputación, que ocultó los posibles efectos adversos de la pandemia sobre la recaudación.

El quid de la cuestión residirá por lo tanto en el análisis del grado de intervención, así como en la orientación de las políticas públicas contra la pandemia. La intervención se centró principalmente en dos ejes de actuación: las medidas de contención del virus y la beneficencia. En el marco competencial de la época, dichas funciones correspondían a la Diputación y, especialmente, a los ayuntamientos.

Empezando por la Diputación y concentrándonos en las medidas adoptadas durante la segunda onda de otoño de 1918, su primera iniciativa fue coordinarse con el gobernador civil. El 20 de septiembre de 1918, el Gobierno Civil publicó una circular convocando una reunión de las juntas municipales de Sanidad ante el aumento de casos de "grippe»". El día 24, la Junta publicó una nota refiriendo la aparición de casos de gripe, «pero ni por su número, ni por su forma, ofrecen importancia, hasta ahora ${ }^{10}$. A partir de octubre, con el aumento de casos, se aplicaron medidas restrictivas para contener la propagación de la pandemia a nivel provincial, como, por ejemplo, el control de viajeros o la desinfección de determinados espacios públicos ${ }^{11}$. A finales de octubre, la Diputación organizó una gran procesión a la basílica de Begoña para pedir el fin de la pandemia a la patrona de Bizkaia ${ }^{12}$. No se aplicaron medidas de confinamiento masivas ni se restringió la actividad indus-

\footnotetext{
${ }^{7}$ Asamblea de Representantes de Ayuntamientos. Bilbao, 08/08/1918, AHFB.

${ }^{8}$ Informes de gestión económica del Ayuntamiento de Bilbao de 1913, 1914, 1915, 1916, 1917, 1919 y 1920, AHFB.

9 "Salud pública», El Noticiero Bilbaíno, 20/09/1918.

10 "Junta Provincial de Sanidad», El Noticiero Bilbaíno, 24/09/1918.

11 "Medidas sanitarias», El Noticiero Bilbaíno, 08/10/1918.

12 «Salud pública», El Noticiero Bilbaíno, 26/10/1918.
} 
trial. En Bilbao ni siquiera se cerraron las escuelas públicas (Ayuntamiento de Bilbao, 1919, p. 45).

La Diputación también ofreció ayuda a los ayuntamientos para contribuir en la organización de los medios de asistencia. La Comisión Provincial aprobó el 9 de octubre de 1918 que el cuerpo de miñones provincial se pusiera a disposición de «los alcaldes para que ayuden a estos en las medidas sanitarias que se adopten en los respectivos pueblos» -el 16 de noviembre se acordó que retornaran a sus funciones regulares. La única ayuda económica aprobada por la Comisión Provincial fue un crédito de 300000 pesetas aprobado el 14 de octubre para «repartir desinfectante y facilitar médicos a los pueblos que lo necesitaran".

El 7 de noviembre, el diputado liberal Alejandro Pisón presentó una moción en el pleno de la Diputación para solicitar la distribución de una ayuda adicional de 500000 pesetas entre todos los municipios con la finalidad de "cubrir las necesidades de los enfermos pobres». En la sesión del 8 de noviembre defendió dicha moción indicando que «aún cuando los médicos dan el alta a los enfermos, estos no pueden acudir al trabajo en mucho tiempo y necesitan que acudan en su auxilio los ayuntamientos, los particulares y ahora la Diputación». Ante esta situación, apuntó que "sabemos que hay infinidad de casas en las que se carece en absoluto de recursos para los padres y los hijos, que no tienen para medicamentos, ni para asistencia, ni siquiera para la subsistencia" y que "hasta ahora los ayuntamientos vienen atendiendo estas necesidades, pero los gastos son tan enormes que han terminado con los recursos». La moción no prosperó por el rechazo de determinados diputados a aumentar el gasto de la institución. Como se vislumbra en las actas, la pandemia no monopolizó, ni mucho menos, la actividad regular de la Diputación, que siguió atendiendo infinidad de cuestiones cotidianas de la administración provincial.

Los ayuntamientos se responsabilizaron de organizar los servicios de asistencia municipio por municipio. Gracias a un informe publicado en 1919 por el Ayuntamiento de Bilbao, conocemos con detalle la actuación del consistorio durante la segunda onda de la pandemia. Su intervención se concentró en tres ejes de actuación: las medidas de desinfección y prevención; la provisión de servicios básicos de cobertura para las familias más necesitadas (comida, ropa, etc.), y el reforzamiento del Cuerpo Médico Municipal para asistir a los enfermos más pobres. A continuación, se muestra el cuadro de gastos por conceptos:

\section{Tabla 3}

Gastos del Ayuntamiento de Bilbao en relación con la segunda onda de la pandemia (en pesetas corrientes)

\begin{tabular}{|lc|}
\hline \multicolumn{1}{c}{ Concepto } & Pesetas \\
\hline Obras de blanqueo y limpieza & $316.464,04$ \\
\hline Bonos de socorro para compra de alimentos & $118.919,86$ \\
\hline Distribución de ropas de abrigo & $108.125,30$ \\
\hline $\begin{array}{l}\text { Sueldos y gratificaciones (principalmente } \\
\text { personal sanitario) }\end{array}$ & $65.553,86$ \\
\hline Otros gastos & $190.468,91$ \\
\hline Gasto total & $799.531,97$ \\
\hline
\end{tabular}

Fuente: Ayuntamiento de Bilbao, 1919.
La intervención de las Administraciones públicas se enmarcó dentro de los límites del modelo de "asistencia liberal» de la época (Esteban de Vega, 2010). Las medidas adoptadas estuvieron más vinculadas a la beneficencia pública y la caridad privada que a ofrecer una respuesta integral a la crisis sanitaria. El gasto en la atención directa de los enfermos fue secundario, limitándose a prestar asistencia domiciliaria a las familias más pobres, «el único segmento de la población cuya asistencia médico-farmacéutica corría a cargo de la Administración» (Gondra y Erkoreka, 2010, p. 149).

La respuesta sanitaria ante la pandemia es una muestra del largo camino que aún quedaba por recorrer en España en el proceso de construcción del Estado de bienestar. La prioridad de las administraciones no fue la atención médica de los enfermos, sino atajar la propagación de la enfermedad y proveer las necesidades básicas a la masa trabajadora incapaz de sobrellevar económicamente sus consecuencias. Detrás de esta actuación se escondía también una finalidad de mantenimiento del orden público.

En cuanto a la cuantificación del esfuerzo presupuestario de las Administraciones, cabe concluir que no resultó una carga excesiva, incluso dentro del estricto esquema de gastos de la hacienda liberal. En el caso de la Diputación, no hay más que ver la figura 6 sobre la evolución de la autonomía financiera para valorar el escaso esfuerzo inversor que supuso desembolsar 300000 pesetas, en un ejercicio en que la recaudación fiscal aumentó en casi tres millones de pesetas, llegando a la cifra de 18862770 pesetas.

Los ayuntamientos se responsabilizaron de la mayor parte del gasto en la lucha contra la pandemia. Durante la segunda onda, el Ayuntamiento de Bilbao desembolsó casi 800000 pesetas en gastos relacionados con la pandemia. A primera vista, esta cifra suponía una carga considerable teniendo en cuenta que el presupuesto de gasto refundido del Ayuntamiento en 1918 fue de 11532283,41 pesetas y que el capítulo de beneficencia no alcanzó las 400000 pesetas. Pero para valorar el esfuerzo presupuestario efectivo es necesario integrar también la vertiente del ingreso. De las 799531,97 pesetas que gastó el Ayuntamiento, tan solo abonó con cargo al presupuesto ordinario 234426,92 pesetas. Primeramente, las 316464,04 pesetas correspondientes al blanqueo de las viviendas se repercutieron a sus propietarios mediante un recargo extraordinario en la contribución territorial. En segundo lugar, cabe subrayar el papel de las suscripciones públicas, un mecanismo de financiación habitual en la época. Gracias a estas suscripciones para particulares y empresas, el Ayuntamiento recolectó 248641,01 pesetas. Es decir, el montante de las donaciones vía suscripciones superó al gasto con cargo al presupuesto municipal. Este mecanismo de financiación también se usó en otros municipios, dándose casos como el del Ayuntamiento de Deusto, donde los ingresos vía suscripción incluso superaron los gastos derivados de la pandemia, dejando un remanente en manos de la corporación (Ayuntamiento de Deusto, 1919).

Por último, hay que destacar que las Administraciones no aplicaron medidas de reactivación económica. Poco más de una década después, en el contexto de la crisis económica de 1929, los gestores republicanos y socialistas de la Diputación y el Ayuntamiento aprobaron grandes inversiones en obras públicas para dinamizar el mercado laboral ante el incremento del desempleo (Erkoreka M., 2020). En cambio, durante la crisis sanitaria de 1918-1920, los gestores contemporáneos no le prestaron especial atención a las consecuencias económicas y laborales de 
la pandemia. Más allá de cuestiones político-ideológicas, esta inacción es un indicativo más del efecto limitado o al menos temporalmente restringido que tuvo la pandemia sobre el mercado laboral.

\section{Conclusiones}

La pandemia de gripe española en Bizkaia afectó de manera desigual en el área metropolitana de Bilbao y en el resto de poblaciones de Bizkaia. Dentro del ámbito urbano, aunque la gripe afectó a todos los segmentos sociales de Bilbao, las zonas de concentración obrera fueron las que sufrieron mayores tasas brutas de mortalidad. Aspectos ligados a la industrialización como el crecimiento urbano anárquico, el hacinamiento o los déficits higiénicos, facilitaron la propagación de la pandemia. La relación causal, en este caso, fue directamente proporcional: a mayor tamaño y densidad de población, mayor incidencia de la pandemia.

En torno a la mitad de la población vizcaína enfermó por la gripe española. En el período álgido, durante la segunda onda, en Bilbao se alcanzó una tasa bruta de mortalidad de 8,4 por 1000 habitantes. El virus tuvo una clara preferencia por los adultos jóvenes. Durante la segunda onda, los adultos jóvenes de entre 20 y 39 años, supusieron el $38 \%$ del total de los fallecidos por gripe y complicaciones respiratorias. Asimismo, los niños menores de 10 años supusieron el 26\%. Es decir, la pandemia afectó preferentemente al núcleo de la población activa.

A la hora de analizar los efectos económicos de la pandemia, es difícil aislarlos de otros condicionantes coyunturales como la guerra o el aumento de precios. Aun así, las fuentes empresariales contemporáneas reflejan que el principal problema de las empresas vizcaínas en el otoño de 1918 y primavera de 1919 no fue la pandemia, sino el intenso ajuste de las economías de guerra a las de paz y la creciente tensión social provocada por la fuerte elevación de precios. De la muestra de empresas analizada se deduce que el sector empresarial no sufrió de manera determinante los efectos de la pandemia sobre la oferta de mano de obra en el contexto posbélico de adaptación a la baja de la producción. Además, la economía vizcaína venía de un periodo expansivo, cuyo pico en forma de beneficios se alcanzó en el ejercicio de 1918; por tanto, el tejido empresarial contaba con reservas para enfrentarse a contingencias. En definitiva, aunque deslindar unos efectos inmediatos de otros a medio y largo plazo es complicado, la pandemia fue un agravante añadido, pero no el principal, en la evolución de la economía vizcaína posbélica y en el contexto de creciente conflictividad social y obrera.

La ausencia de un sistema de previsión social eficiente que garantizara una cobertura mínima a los trabajadores enfermos condicionó la respuesta de las Administraciones públicas contra la pandemia. La intervención de las Administraciones públicas se enmarcó dentro de los límites del modelo de «asistencia liberal». La actuación de las instituciones se centró principalmente en adoptar medidas de contención y en proveer servicios básicos como ropa y comida a las familias más necesitadas, dejando en un segundo nivel la atención médica de los enfermos. La intervención de las Administraciones públicas estuvo más orientada a la beneficencia y la promoción de la caridad privada -vinculada a un objetivo de mantenimiento del orden público y la paz social-, que a ofrecer una respuesta integral a la crisis sanitaria y social.

La huella directa de la pandemia fue reducida en los presupuestos de la Diputación de Bizkaia y del Ayuntamiento de
Bilbao, quedando minimizada por la coyuntura de expansión presupuestaria que experimentaron estas instituciones durante los años de la guerra.

\section{Fuentes}

Archivo Histórico Foral de Bizkaia (AHFB). Libros de actas de la Comisión Provincial y del Pleno de la Diputación (19171921), estadísticas de tributación (1910-1920) y fondos empresariales.

Archivo Municipal de Bilbao (AMB). Boletín Mensual de Estadística Sanitaria de Bilbao (1917-1920).

Información: Órgano Oficial de la Cámara de Comercio de Bilbao (1918-1919).

El Noticiero Bilbaíno (1918-1919).

Registro de defunciones y nacimientos de los registros civiles de los municipios de la ría de Bilbao.

\section{Bibliografía}

Agirreazkuenaga J. y Alonso E. J. (eds.) (2014). Historia de la Diputación Foral de Bizkaia (1500-2014). Bilbao: Diputación Foral de Bizkaia.

Alonso, E. J. (1995). El Concierto Económico (1878-1937). Orígenes y formación de un Derecho Histórico. Oñati: IVAP.

Alonso, E. J. (1997). «La fiscalidad empresarial en Vizcaya 1914-1935. Un beneficio del Concierto Económico» Hacienda Pública Española, 141-142, 3-26.

Alonso, E. J. (2000). La Mutua Vizcaya Industrial. 1900-2000. Un siglo de protección social en Vizcaya. Bilbao: Mutua Vizcaya Industrial.

Alonso, E. J., Erro, C. y Arana, I. (2016). Santa Ana de Bolueta, 1841-2016. Renovación y supervivencia en la siderurgia vizcaína. Bilbao: Santa Ana de Bolueta.

Ansart, S., Pelat C., Boelle P., Carrat F., Flahault, A. y Valleron, J. (2009). «Mortality Burden of the 1918-1919 Influenza Pandemic in Europe», Influenza and Other Respiratory Viruses, 3, 99-106.

Arbaiza, M. (1999). «Urbanización y condiciones de vida en Vizcaya (1877-1930): aproximación a las causas sociales de la mortalidad infantil y juvenil», Historia Contemporánea, 18, 209-251.

Athukorala P. y Athukorala C. (2020). The Great Influenza Pandemic of 1918-20. An interpretative survey in the time of COVID-19. WIDER Working Paper, 2020/124.

Ayuntamiento de Bilbao (1919). Memoria de la organización y funcionamiento de los servicios municipales para combatir la epidemia gripal. Bilbao: Imp. Lerchundi.

Ayuntamiento de Deusto (1919). Memoria-Informe sobre los medios que utilizó el ayuntamiento para combatir la epidemia. Bilbao: Imp. José Ausín.

Barro, R. J., Ursúa, J. F. y Weng, J. (2020). The coronavirus and the Great Influenza Pandemic: lessons from the "Spanish Flu» for the coronavirus's potential effects on mortality and economic activity. NBER Working Paper Series, 26866.

Basco, S., Domenech, J., y Roses, J. R. (2020). The Redistributive Effects of Pandemics: Evidence on the Spanish Flu. Working Papers in Economic History, 2020/05.

Bernabeu-Mestre, J., Esplugues, J. X., Galiana-Sánchez, M. E. y Trescastro, E. M. (2016). «Pasado y presente de la nutrición en España», ANS, 23 (2), 27-38.

Chowell, G., Erkoreka, A., Viboud, C. y Echeverri-Dávila, B. (2014). «Spatial-temporal excess mortality patterns of the 1918-1919 influenza pandemic in Spain», BMC Infectious Diseases, 14 (1), 1-12.

Comín, F. (2010). «Las fases históricas de la seguridad social en España. (19002000)», Revista de la Historia de la Economía y de la Empresa, 4, 65-93.

Echeverri, B. (1993). La Gripe Española: la pandemia de 1918-1919. Madrid: CIS-Siglo XXI.

Echeverri, B. (2018). «En el centenario de la gripe española. Un estado de la cuestión», Revista de Demografía Histórica, 36 (1), 17-42.

Erkoreka, A. (2006). La pandemia de Gripe Española en el País Vasco (1918-1919). Bilbao: Museo Vasco de Historia de la Medicina.

Erkoreka, A. (2010). «The Spanish influenza pandemic in occidental Europe (1918-1920) and victim age», Influenza and Other Respiratory Viruses, 4, 81-89.

Erkoreka, A. (2017). «Y se le llamó gripe española», Investigación y Ciencia 2020/6, 52-53.

Erkoreka, A. (2020). Una nueva historia de la gripe española. Paralelismos con la COVID-19. Pamplona-Iruña: Lamiñarra. 
Erkoreka, M. (2017). The public finances of Araba, Biscay and Gipuzkoa during the dictatorship, the Great Depression and the II Republic (1925-1937) [tesis doctoral]. UPV/EHU.

Erkoreka, M. (2018). "The Basque and Swiss fiscal systems building processes as a source of lessons for the European integration process», en Martínez, G. e Irujo X. (eds.), International Perspectives on fiscal federalism: the Basque tax system. Reno: Center for Basque Studies, pp. 119-137.

Erkoreka, M. (2020). Arabako, Bizkaiko eta Gipuzkoako finantza publikoak eta Ekonomia Ituna 1929ko krisi ekonomikoaren garaian (1925-1936). Bilbao: UPV/EHU.

Esteban de Vega, M. (2010). "La asistencia liberal en la España de la Restauración» Revista de la Historia de la Economía y la Empresa, 4, 49-62.

Fuentes, M. y García, C. (2015). «España y la Gran Guerra: un análisis historiográfico a la luz del centenario», Î́ndice Histórico Español, 128, 97-136.

Goldstein, J. R. y Lee, R. D. (2020). Demographic perspectives on mortality of COVID-19 and other epidemics. NBER Working Papers, 27043.

Gondra, J. y Erkoreka, A. (2010). «El cuerpo médico municipal (1897-1937) y la pandemia de gripe española en Bilbao (1918-1920)», Bidebarrieta,, 21, 139152.

González Portilla, M. (ed.) (2001). Los orígenes de una metrópoli industrial: la Ría de Bilbao. Bilbao: Fundación BBVA.

González Portilla, M. y Zarraga, K. (eds.) (1998). Hospital de Bilbao y transición sanitaria. Enfermedad y muerte en Vizcaya, 1884-1936. Bilbao: Hospital de Basurto.

González Portilla, M., Hernando J. y Urrutikoetxea J. (2018). «Primera Industrialización, urbanización e indicadores de bienestar. La Ría de Bilbao 1877-
1930», en Otero, L. y De Miguel, S. (eds.), La escuela y la despensa: indicadores de modernidad. España, 1900-1936. Madrid: Catarata, pp. 52-81.

Nadal, J. (1986). La población española (siglos XVI a XX). Barcelona: Ariel.

Novo, P. A. y Zarraga, K. (2019). «Uses and users of water in Bilbao, c. 1890-1910: a social-spatial analysis», Urban History, 47(1), 86-105.

Pérez Castroviejo, P. M. (2002). «La formación del sistema hospitalario vasco: administración y gestión económica, 1800-1936», TST, 3-4, 73-97.

Pérez, V., Reher, D. y Sanz, A. (2015). La conquista de la salud. Mortalidad y modernización en la España contemporánea. Madrid: Marcial Pons.

Pons, J. y Silvestre J. (2010). Los orígenes del Estado del bienestar en España, 19001945: los seguros de accidentes, vejez, desempleo y enfermedad. Zaragoza: Prensas Universitarias de Zaragoza.

Porras, M. I. (1997). Un reto para la sociedad madrileña: la epidemia de gripe de 1918-1919. Madrid: Editorial Complutense.

Roda, D. (1931). La beneficencia en Vizcaya. Bilbao: Elexpuru Hermanos.

Sociedad de Seguros Mutuos de Vizcaya (1919). Memoria de 1918. Bilbao: Ugalde y compañía.

Valleron A. J., Cori, A. y Valtat, S. (2010). «Transmissibility and geographic spread of the 1889 influenza pandemic», PNAS, 107, 8778-8781.

Villanueva, A. (1985). Historia social de la tuberculosis en Bizkaia 1882-1959. Bilbao: Diputación Foral de Bizkaia.

Vitoria, M. (1978). Epidemias de cólera en Vizcaya en el siglo XIX. Bilbao: La Gran Enciclopedia Vasca. 